\title{
A project management approach to long-term preservation of optical media tasks
}

\author{
Arian Rajh \\ Department of Information and Communication Sciences \\ Faculty of Humanities and Social Sciences, University of Zagreb \\ Ivana Lučića 3, Zagreb, Croatia \\ Agency for Medicinal Products and Medical Devices \\ Ksaverska c.4, Zagreb, Croatia \\ rarian_sp@yahoo.com
}

\section{Summary}

Optical media used in common practice are rarely suitable for long-term preservation (LTP) tasks, they are more a mean of transmission of records between the producer of records and the organisation/archive (any archive in broader sense). Migration is a LTP method which can be used after the act of receiving records, but its dynamics may vary and it can be implemented as a routine process or through project management approach. The author investigates migration process in Croatian National Competent Authority on the example of medicinal products records on CDs and DVDs. Studied projects belong to the same organisation and domain of records. The author investigates complexity of project management approach to migration of optical media and concludes with recommendations on setting up such projects.

Keywords: Documents and records management system, long-term preservation (LTP), migration of optical media, migration process, project management, XML

\section{Introduction}

Optical media are commonly used for transfer of digital content, among other media and channels like portals or USB drives. Producers of records are not always aware of archival requirements related to media and organisation of content of these media. Optical carriers can be damaged through usage in business processes. These are just some initial problems related to the preservation of digital records on original optical media. With migration process once established, organisations that receive records on these media may shift their focus from characteristics related to media to other qualities of records. ${ }^{1}$ Then the em-

\footnotetext{
${ }^{1}$ INTERPARES 2 Project. Preservation Task Force Report. Pages 11-12. http://www.interpares. org/book/interpares_book_f_part3.pdf (accessed 29/4/2015)
} 
phasis is given to preservation of content and evidential quality of records that represents that content. Of course, original media type should be mentioned in archival metadata. Overall tendencies in long-term preservation (LTP) moved away from keeping the original media in order to preserve contained information. Archival community takes widespread optical media (and non-archival storage media in general) for means of transfer of submission information packages (SIP), due to their volatility during manipulation and relatively short life expectancy. Optical media carriers are used for ingest of content from source storage to document and records management system, and for export from the system or for dissemination to other systems or users. Digital record is a set of data collected from the storage, dispatched to a memory, represented by review or edit software, and shown on user's screen - so authenticity of digital record is not necessarily tied in with the notion of digital media as a carrier. Consequently, long-term preservation attempt may go by without paying attention to the conservation of media. The question of preservation of optical media relates to the more general question of preservation of physical, logical and conceptual level of record, and the decision about what do we want and need to preserve in particular case. ${ }^{2}$ This just means that the notion of authenticity differs from the one in world of paper and has to be ensured differently.

In general, preservation tasks related to the content transferred via optical media should be performed regularly. Records on optical media carriers that have not yet been migrated into document and records management system are in risk while awaiting copying. However, if creator or archive accumulated a large amount of compact discs over time and plans to migrate them in one or several efforts, preservation tasks should be set up as projects. Project is a unique set of activities with limited duration and resources and these activities must lead to planed and measurable result(s). ${ }^{3}$ Beside results and activities, project should have clear purpose, defined scope (e.g. number of CDs/DVDs or particular records series), plan, schedule, budget, milestones for activities, verifiable indicators for results, analysed risks, and recognised issues that can be solved during implementation.

Organisation (creator and its archive) studied in this article is HALMED, Croatian National Competent Authority for regulation of medicinal products, medical devices and homeopathic medical products. ${ }^{4}$ HALMED implemented docu-

\footnotetext{
${ }^{2}$ Stančić, H. Theoretical model of persistent preservation of authenticity of digital information objects, PhD dissertation. Zagreb: Faculty of humanities and social sciences, 2005, p. 15-16

${ }^{3}$ National competence baseline, Croatian version 3.0, Zagreb: Croatian association for project management, 2008, p. 15. http://capm.hr/preuzimanja/ (accessed 30/4/2015)

${ }^{4}$ Agency for Medicinal Products and Medical Devices (HALMED) is National Competent Authority for registration of medicinal products, medical devices and homeopathic medicinal products in accordance with legislation of the Republic of Croatia (http://www.halmed.hr/?ln=en\&w= o_agenciji).
} 
ment and records management system in 2014 (Digital archival information system, DAIS). System was developed on FileNet P8 platform. It consists of several modules (Content navigator, Enterprise records, Migration and ingest module and other) and two repositories. Repository called Records object store (ROS) is controlled by document management module (content navigator). File plan object store (FPOS) is controlled by records management module (Enterprise records) and by connected archival application Pismohrana. ${ }^{5}$

\section{Migration}

Migration motivator or drive in the case of submitted optical media is prevention of media decay. ${ }^{6}$ There are several types of migration according to OAIS model/standard, from simple migration to complex migrations - refreshment, replication, repackaging and transformation. ${ }^{7}$ Refreshment is migration of records from media to media of the same generation, without alterations of the information packages. Replication comes down to migration of packages to new media, repackaging ${ }^{8}$ includes changes on the physical level, and transformation does not rule out changes on logical level. Transformation can be reversible or non-reversible (which is not recommended).

Migration of optical media in the National Competent Authority HALMED includes: (1) registration of SIP package on optical media into archival application with barcoding of the physical technical unit (disc), (2) copying folders and files into folder with the same barcode, ${ }^{9}$ (3) migration of files by document and

${ }^{5}$ DAIS document and records management system was implemented by IPA 2009 TAIB project Preparations for eCTD and implementation of DAIS, proposed and managed by A. Rajh and implemented by Ericsson Tesla (business processes modelled by AAM Consulting). Archival application Pismohrana was developed by Omega Software in 2013. Please see: HALMED is implementing a one year IPA project "Preparation for eCTD and implementation of digital archive information system", http://www.halmed.hr/?ln=en\&w=novosti\&d=2014 \&id=1053, 1/4/2014 (accessed 30/4/2015); Preparations for eCTD and implementation of digital archival information system, http://www.safu.hr/en/news/preparations-for-ectd-and-implementation-of-digital-archival -information-system, 17/9/2014 (accessed 30/4/2015).

${ }^{6}$ Reference model for an open archival information system (OAIS), Recommended practice CCSDS 650.0-M-2. June 2012. http://public.ccsds.org/publications/archive/650x0m2.pdf, p. 5-3 (accessed 30/4/2015)

${ }^{7}$ Reference model for an open archival information system (2012), ibid., p. 5-4 and further. For other definitions of the term related to file version please see Stančić (2005), ibid., page 82; Shepherd, Elizabeth and Yeo, Geoffrey, Managing records - a handbook of principles and practice, London: Facet Publishing, 2003, p. 198

8 "The contents of the three files are moved to three new files on another media type, with a new directory and file implementation. Even if all the directory and file names have been preserved in the transfer, a Repackaging has taken place because the bits used to represent the Packaging Information have changed.", Reference model for an open archival information system (2012), ibid., p. 5-6

${ }^{9}$ See figure 1. 
records management system DAIS into new digital technical unit, (4) automatic registration of new digital technical unit into archival application linked to DAIS, and (5) automatic file conversion into PDF/A. File conversion is made using Aspose software (www.aspose.com) integrated with DAIS system. Details of the whole migration process will be presented later in this article. The main characteristic of this process in HALMED are:

- content of the package are migrated to storage of different type

- folder structure is kept on conceptual level ${ }^{10}$ (in document module of DAIS system), although storage itself is organised differently (metadata in database and objects in file storage until its replacement with archival storage, i.e. EMC Isilon or similar) ${ }^{11}$

- content is linked with original unit through barcode identifier provided by archival application

- metadata are re-used through this linking

- standardisation of file format (PDF/A) wherein the process is reversible (previous version is stored by document and record management system; system preserves all versions, but question is for how long previous versions in non-archival formats may be accessed and used)

- process is well-documented by DAIS and prescribed in formal internal act (standard operative procedure)

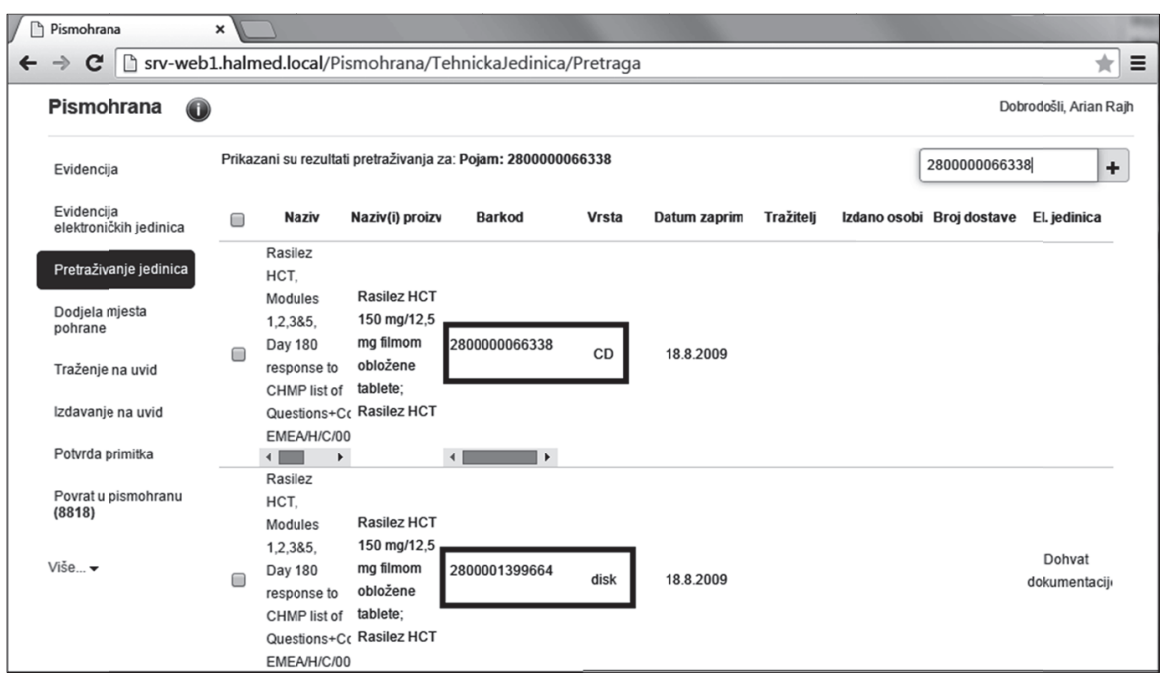

Figure 1: Usage of barcode identifier for linking original information package and digital package (Pismohrana archival application in HALMED, developed by Omega Software)

\footnotetext{
${ }^{10}$ See figure 2.

${ }^{11}$ See figure 3. For more about selection of storage please see: Critical Capabilities for Scale-Out File System Storage, 27 January 2015, http://www.gartner.com/technology/reprints.do?id =128XVMOC\&ct $=150130 \& \mathrm{st}=\mathrm{sb}($ accessed $24 / 7 / 2015)$
} 


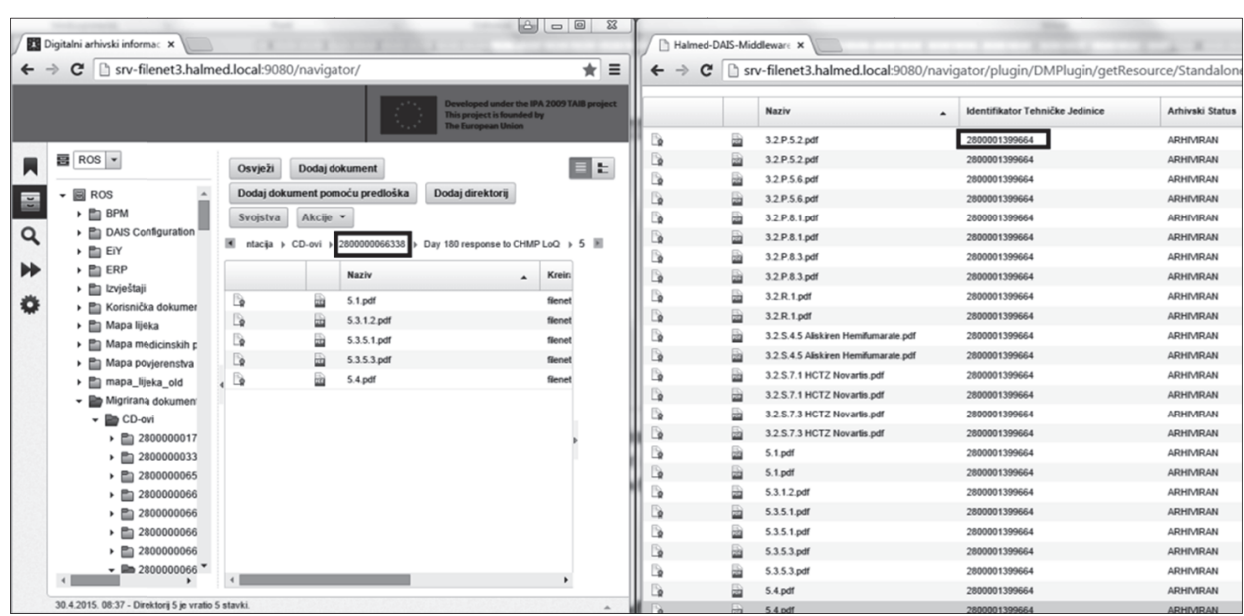

Figure 2: Presentation of structure in document and records management system (FileNet based DAIS system, developed by Ericsson Nikola Tesla)

Process has features of reversible transformation and it combines standardisation of format and OAIS approach, because DAIS system was developed following OAIS principles. ${ }^{12}$

\begin{tabular}{|c|c|c|c|c|}
\hline 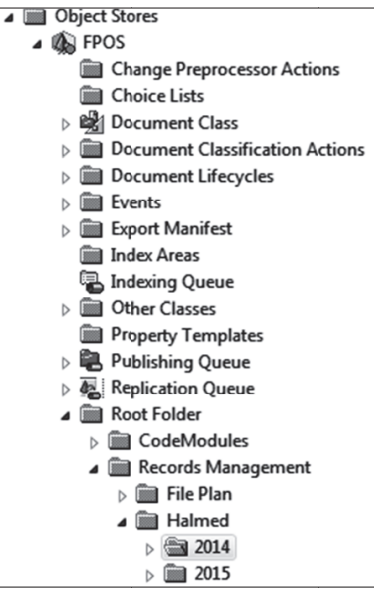 & 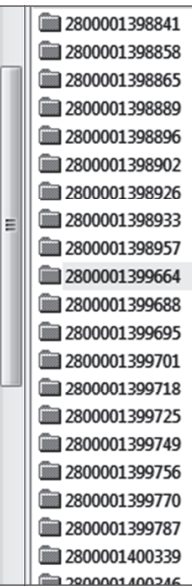 & 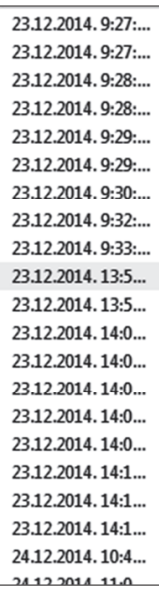 & $\begin{array}{l}\text { pism... } \\
\text { pism... } \\
\text { pism... } \\
\text { pism... } \\
\text { pism... } \\
\text { pism... } \\
\text { pism... } \\
\text { pism... } \\
\text { pism... } \\
\text { pism... } \\
\text { pism... } \\
\text { pism... } \\
\text { pism... } \\
\text { pism... } \\
\text { pism... } \\
\text { pism... } \\
\text { pism... }\end{array}$ & $\begin{array}{l}\text { Electron... } \\
\text { Electron... } \\
\text { Electron... } \\
\text { Electron... } \\
\text { Electron... } \\
\text { Electron... } \\
\text { Electron... } \\
\text { Electron... } \\
\text { Electron... } \\
\text { Electron... } \\
\text { Electron... } \\
\text { Electron... } \\
\text { Electron... } \\
\text { Electron... } \\
\text { Electron... } \\
\text { Electron... } \\
\text { Electron... } \\
\text { Electron... } \\
\text { Electron... } \\
\text { Electron... } \\
\text { E.c... }\end{array}$ \\
\hline
\end{tabular}

Figure 3: Content in FPOS store (FileNet based DAIS system, developed by Ericsson Nikola Tesla)

These were technical characteristics of optical discs long-term preservation process in HALMED. Below in the article process shall be reviewed from the perspective of organisation of job - (A) as regular use cases (or daily work) and (B) as projects dealing with backlog incurred before implementation of DAIS.

\footnotetext{
${ }^{12}$ Stančić (2005), ibid., p. 92, 102, 103, 104
} 
The very need for similar preservation process as described in this article was recognised in HALMED in 2008, during pre-research or pilot study of optical media long-term preservation applicability.

\section{Pre-research of suitability of optical media for LTP (pilot project)}

Pilot study was designed by Stančić, Rajh and Tušek and conducted by Faculty of Humanities and Social Sciences students in HALMED in May 2008. ${ }^{13}$ Students were checking the readability of optical media and defective media were detected. 279 media stored in hard CD cases or plastic sleeves were tested with CDR media code identifier, CD-R diagnostic, and DVDisaster applications. For $60 \mathrm{CDs}$, it was not possible to determine the date of recording. Some CDs were recorded in 2001, and majority of CDs were recorded between 2005 and 2006. Aim of testing with CDR media code identifier was to determine disc manufacturer and to see if ATIP (absolute time in pregroove) method of putting data is the same for all CDs (and it was not the case). CD-R diagnostic helped pilot project team to determine recording application, the recording date and organic dye layer (cyanine, azo, phthalocyanine). ${ }^{14}$ Unreadable CDs were recorded using applications that CD-R diagnostic could not determine. DVDisaster showed us existence of unreadable sectors of media. $171 \mathrm{CDs}$ were without any problems (61\%), $75 \mathrm{CDs}(27 \%)$ had problems ${ }^{15}$ and $33 \mathrm{CDs}(12 \%)$ were unreadable. Among CDs of branded manufacturers $8 \%$ were unreadable, and among CDs of unknown brand this rate was $14 \%$. Pilot study was presented at 10/13th International information technology and journalism conference and in the European Medical Agency in London, on Telematic implementation group for electronic submission meeting, so it had some influence on national agencies' practices through group's message to agencies. Results of this pilot research indicated volatility of CDs and HALMED decided to store content of optical disks on other media, precisely on servers and archival storage. Immediate actions were

${ }^{13}$ Stančić, H.; Rajh, A.; Tušek, M. Are optical disks suitable for LTP?, 10/13th International Conference Information Technology and Journalism Collaborative Media and Content Management 15-23/5/2008. Pilot study was done as Digital preservation Europe Croatian Team's activity. Students on practice were: M. Borgudan, T. Pleše and T. Pavičić.

${ }^{14}$ Results of testing related to relation of dye layer and deterioration Stančić/Rajh/Tušek pilot study followed trend recognised in Slattery at al., Stability comparison of recordable optical discs, Journal of research of the NIST, Vol. 109, No. 5, 2004, p. 520 (“...phthalocyanine as the dye and silver and gold alloy as reflective layer, is far more stable than any of the other samples..."). Results in Stančić/Rajh/Tušek pilot study were $44 \%$ of errors for cyanine and azo dye (8/18) and $25 \%$ of errors with phthalocyanine (25/98). For 163 CDs CD-R Diagnostic application could not detect type of layer (with $25 \%$ or errors and $33 \%$ of unreadable CDs).

15 "The end of life of a disc can be defined as the time when uncorrectable error occurs. Although the disc may still be readable after this point, some information has been lost.", Slattery at al. 2004 (ibid.), p. 518. 
purchase of cabinets for optical media and publication of instructions for submitting documentation. ${ }^{16}$

\section{Projects initiated for migration of accumulated optical discs and use cases for projects and regularly performed work}

Realisation of that preservation planning decision from 2008 was supported by implementation of DAIS system in 2014. That is why HALMED included migration of accumulated CDs/DVDs during IPA project, initiated other projects aiming to migrate further quantities of media, and designed migration use case (new support process for migration of new accruals and for migration projects). Roll-out of these use cases happened in December 2014. Process (a set of use cases) was facilitated by migration module of DAIS system, based on FileNet P8 platform and customised by Ericsson Tesla during IPA 2009 TAIB project (figure 4).

The process consists of several use cases (figure 5): use cases for ingest of digitised SIP packages of paper technical units and use cases for migration of CDs. Use cases for CDs do not cover CD that have to be uploaded in business applications (review system for eCTD ${ }^{17}$ dossiers, application for medical devices etc.). CDs for migration through DAIS must be previously recorded into archival application so links between original media and migrated content can be created. CDs/DVDs have to be copied on server mapped to DAIS in folder named after barcode of original media. Generic XML file with location and operation instructions have to be copied into folder named after barcode of original disc. After that, it is necessary to start migration module of DAIS and to run function that validates copied XML. Migration procedure starts after validation of XML. XML prescribes migration operations for CD/DVD as a SIP and its representation in logical organisation of AIPs in DAIS. Then XML prescribes migration operations performed sequentially on each file from CD/DVD. After migration, XML prescribes post-import operations. Post-import operations include linking new AIP (or migrated content) with recorded information about physical CD/DVD disc in archival application Pismohrana. Barcode identifier of original physical disc is used to link the disc and AIP. After these two entities are linked, archival application creates new description of migrated AIP and copies re-usable metadata from description of original physical disc to descrip-

\footnotetext{
${ }^{16}$ In which it was prescribed that optical media should be submitted in a hard cover, http://www.halmed.hr/?ln=en\&w=lijekovi\&d=dokumentacija (accessed 5/5/2015)

${ }^{17}$ eCTD or electronic Common Technical Document is electronic format of medicinal product's dossier with prescribed structure, files and folders naming conventions, records in PDF format and metadata in XML files. Dossiers consist of 5 modules: module for regional administrative records, module for summaries, module for quality related documentation, non-clinical and clinical module. For more information visit: http://estri.org/eCTD/.
} 
tion of AIP. After migration is done, it is required to check access possibility to AIP through particular DAIS query or through query in archival application.

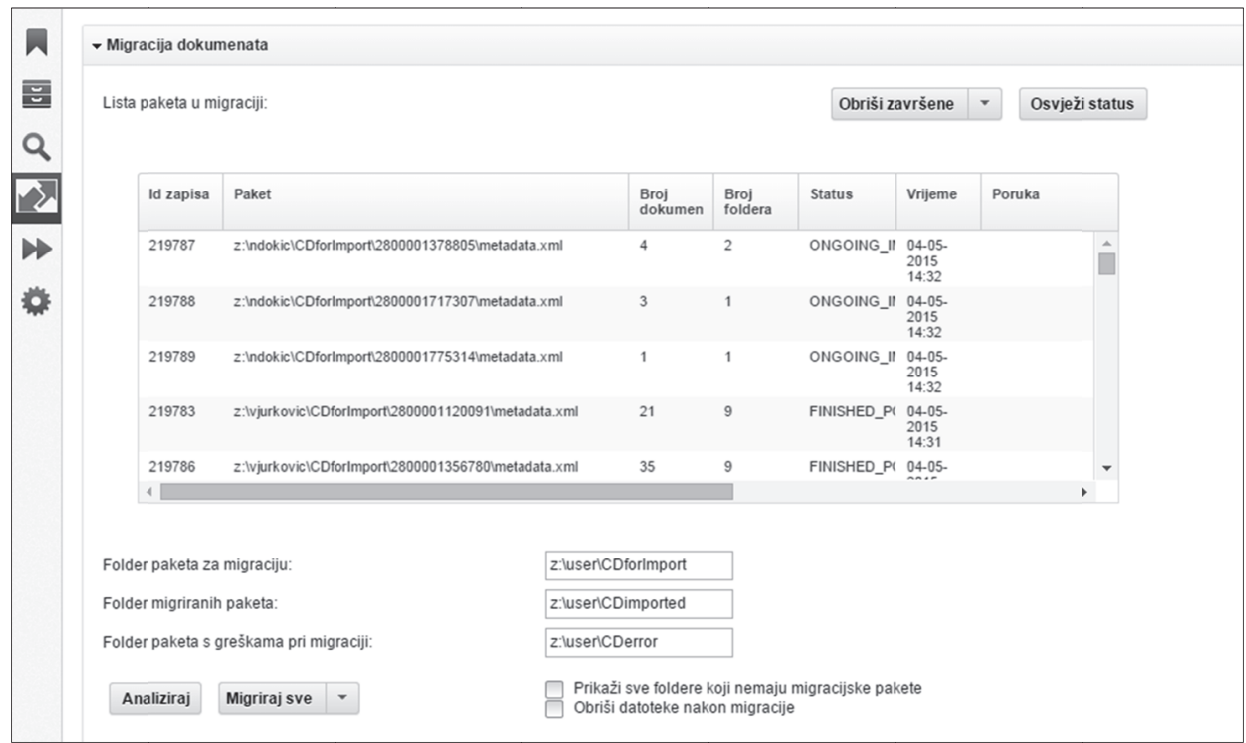

Figure 4: DAIS module for migration and ingest (developed by Ericsson Tesla for HALMED)

There were 4,567 CDs/DVDs migrated through this process during IPA 2009 TAIB project by Ericsson Tesla. Total capacity of migrated CDs/DVDs was 570 GB and they contained 376,501 files. There were also 79 unreadable CDs/DVDs $(1.73 \%){ }^{18}$ These 4.5 thousands CDs/DVDs were in project terms of reference and project scope. There were still 13.500 CDs left in HALMED after IPA 2009 TAIB project, without counting new CDs that HALMED received on daily basis. Although new CDs/DVDs are mostly in eCTD format and they are foreseen to be uploaded in business applications, so regular migration process should not be used for all of them, HALMED had to solve its backlog problem and migrate $\mathrm{CDs}$ before their deterioration.

That is why HALMED suggested a student practice proposal to Department of Information and Communication Sciences (Faculty of Humanities and Social Sciences, Zagreb). The proposal was adopted by the Faculty and practice was designed as 14-work-days project with the team of four students, practice mentor and project manager. ${ }^{19}$ Expected project results were migrated optical media

\footnotetext{
${ }^{18}$ Final Report for the Contract "Development of the Digital Archive information system software in the Agency for Medicinal Products and Medical Devices, Republic of Croatia” EuropeAid/ 132507/D/SER/HR, Ericsson Tesla, 2014, p. 37.

${ }^{19}$ Students on the project - A. Vuk, K. Škrabo, N. Dokic, V. Jurkovic. Manager for this project was B. Romčević. Scope of the project was min. 3.500 up to $5.000 \mathrm{CDs}$ and it was set up after initial migration tests. Project with students started on 4 May and ended on 22 May 2015. After
} 
in the DAIS system and facilitation of records management and usage. The team that designed the project recognised several risks related to it, from scope related risks, technical and human errors, unreadability related risk, to delays associated with technological environment. Project was divided into three phases, the first one comprised preparation and training, second phase was migration process itself, and third phase dealt with final check-up before sending migrated discs for destruction. Project team used mapped server drive for copying, DAIS migration module for migration, and queries of archival application or DAIS Content navigator for verification. Activities of project team followed migration process shown in third lane of figure 5 (tasks 16, 17, 18, 19, 20). Physical destruction of the media had to be documented through archival application and each barcode had to be listed. Project was planned in ProjectLibre application (with Gantt chart, work breakdown structure and list of resources). ${ }^{20}$ Students migrated 3,812 CDs/DVDs in May 2015, and error rate was 1.27\% (49 CDs were unreadable and they were not migrated into DAIS). Project plan in ProjectLibre application was monitored by project manager on daily basis.

HALMED decided to perform migration of last backlog of CDs/DVDs with its internal team because any delay could result with further increase of number of unreadable CDs. This work was planned as a follow-up project that took place after student practice project. Results in this ongoing project are 5,668 CDs/DVDs migrated by internal employees by 23.7.2015. Current error rate is $2.49 \%$ or $141 \mathrm{CD} / \mathrm{DVD}$.

HALMED started migrating new optical discs as they came to the Agency from spring 2015. Predictions based on project experience with students and project plan for follow-up project with internal employees indicate that migration of the backlog optical discs should be finished by the end of September 2015.

ending this project with students, HALMED initiated follow-up project with its own employees in June 2015.

${ }^{20} \mathrm{http}: / /$ www.projectlibre.org/, downloaded and installed in April 2015. 


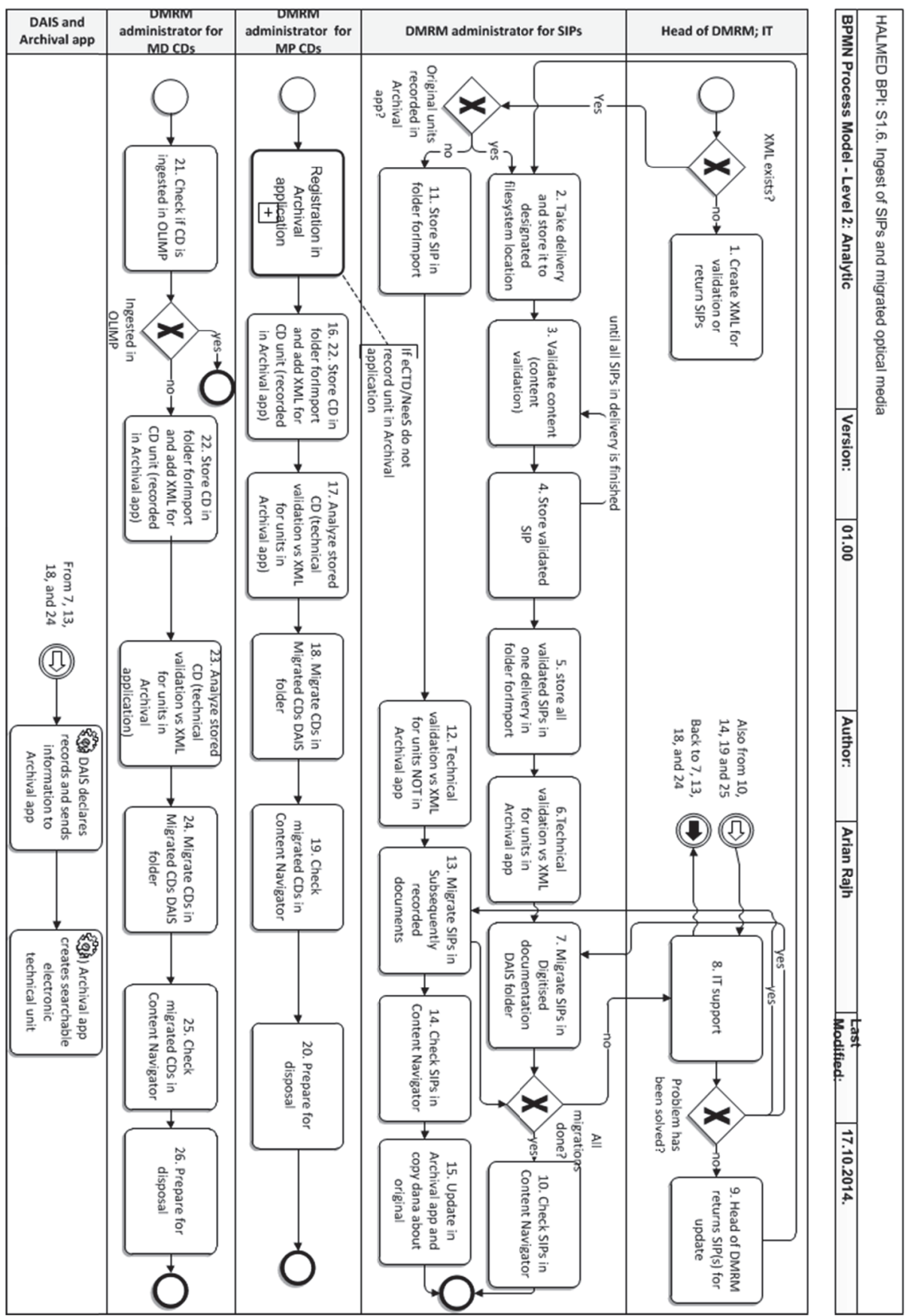

Figure 5: Migration and ingest process - tasks, process scheme created by A. Rajh in Croatian was included in his article Sustavi za upravljanje digitalnom dokumentacijom - nove mogućnosti $i$ novi izazovi za stvaratelje $i$ arhive, Arhivski vjesnik (Bulletin d'archives) 58/2015 (forthcoming 2015). English version of model was added to this article to show complexity of the process. 


\section{Quality, project risks, issues - project management}

Quality in these projects is ensured by validation function in Migration and ingest module of DAIS and by checking the links in DAIS from archival application. For CDs with errors, HALMED will ask applicants (pharmaceutical representations and companies) for their copies after follow-up project ends. Risk related to unreadability occurred in much smaller ratio than during the pilot project from 2008. Sample in the pilot project was relatively small and that explains a large error rate. Second risk that occurred was risk related to DAIS system stress because several students (or employees) used to start migration at the same time. This issue was mitigated by sequencing of migration procedure. Beside those risks, another risk related to CDs occurred during migration of results of digitisation projects: some of the older CDs were inserted into binders with paper documents by HALMED's applicants. This was recognised earlier during the pilot project in 2008 as a bad practice and applicants were asked to submit CDs in separate hard covers. ${ }^{21}$ Company that digitised paper documents marked those CDs with identifiers identical to identifiers of paper binders in which they were inserted. This risk can be handled by adding information about existence of original optical media in archival application and linking this information with migrated content. Although migration projects for CD/DVD discs are not categorised as large scale projects, and writing Lessons learned documents is not mandatory according to HALMED's project management methodology, recommendation based on projects experience would be to migrate content of optical media regularly or to establish very determinative technical environment for migration projects and very strict project monitoring mechanisms.

HALMED is not a project management oriented organisation, but it runs a large number of projects. In 2014 HALMED designed its project management methodology that can also be used for any internal migration project. Methodology was designed by A. Rajh, with an advisory help of R. Gospodnetić, team leader of AAM Consulting, a company engaged in IPA 2009 TAIB project for business process management. It consists of four broad phases ${ }^{22}$ and twenty two steps (from initial agreement between project proposer and his or hers manager, to creation of project proposal document, creation of project environment in DAIS, creation of project charter, project plan and risk plan, all the way to reporting activities. HALMED methodology has some elements similar to Project Cycle Management, TenStep and PRINCE2. Projects governance and portfolio management include approving projects by unit managers, internal project management working group and Head of the Agency. Monthly monitoring is done

\footnotetext{
${ }^{21}$ See note 16 .

${ }^{22}$ Project management methodology phases on Croatian: Formulacija, Inicijacija, Razrada i evaluacija, Upravljanje projektom
} 
by Agency's project management working group. Exceptions during implementation of projects are handled in internal procedure of change management, e.g. changing the scope or handling project issues. For large projects (over 200.000 HRK and/or 12 months of implementation) HALMED's methodology prescribes using additional analytical tools and writing Lessons learned documents and other documents with extensive project related information. HALMED also engaged project consultancy Primakon for training in project management and it comprised project management principles and workflow of HALMED internal project management procedure.

\section{Conclusion}

Long term preservation of digital records is very demanding, and it can help a little if organisation cuts optical media unpredictability out of the equation. Of course, this does not mean that organisation or archive should not check regularly server storage or archival storage subsystem, do the backup frequently and according to the backup plans, and design its disaster recovery and business continuity process. Recommendation is to do migration from widespread recordable optical media to records management or file systems as daily process or to prescribe submission of more stable media. These media could be archival grade optical media, long-term backup DVDs or DTD discs with metal-ceramics inorganic layer. It is important to plan and execute migration projects according to the needs of the organisation. Using more stable optical carriers, like DTD discs with 160 years life expectancy stated after accelerated aging tests or other transfer carriers with longer life expectancy, will not solve all preservation problems associated with textual records - because it is not just the records' carriers archivists should be worried about. Relying on archival standards for file formats due to their known specifications that could be used for development of viewer and editor software in the future is much safer. Using embedded noncopyrighted fonts, typographically similar to common fonts for textual content, where they can be applied, is another proactive archival measure. Using standardised metadata for description is also recommended. Ensuring that migrated content is protected in document and records management system of some organisation, competent service provider or archival organisation is another level of archival custody. If such a system on top of preservation mechanisms ensures authenticity of its digital holding, this could provide public trust in the records creator, custodian or archive.

Documents and records management systems like DAIS have advantage before file systems because they can support migration process better and they can document it, which is essential. However, day-to-day migration of discs is easier (once established) so organisation or (its) archive can focus its LTP plans on file formats, reader applications, metadata, font fixing etc. If organisation or archive accumulated or inherited backlog, it should launch a migration project or a LTP programme of projects, but it has to be done with formal project man- 
agement intellectual tools. Approach should strictly follow some internal or acquired methodology. Migration projects are easier to plan and execute if organisation has experience from similar projects or from migration tests, and if it owns appropriate technological environment to facilitate migration tasks.

\section{References}

Critical Capabilities for Scale-Out File System Storage, 27 January 2015, http://www.gartner. com/technology/reprints.do?id=1-28XVMOC\&ct=150130\&st $=$ sb (accessed 24/7/2015)

Final Report for the Contract "Development of the Digital Archive information system software in the Agency for Medicinal Products and Medical Devices, Republic of Croatia" EuropeAid/132507/D/SER/HR, Ericsson Tesla, 2014

HALMED is implementing a one year IPA project "Preparation for eCTD and implementation of digital archival information system", 1/4/2014 http://www.halmed.hr/?ln=en\&w=novosti\&d= 2014\&id=1053 (accessed 30/4/2015)

Instructions for applicants for submitting the conventional dossier for medicinal products, 2009, http://www.halmed.hr/?ln=en\&w=lijekovi\&d=dokumentacija (accessed 5/5/2015)

INTERPARES Project. Storage Media (Characteristics and Composition) - Media. Draft appendix. October 2001. www.interpares.org/documents/media.pdf (accessed 30/4/2015)

INTERPARES 2 Project. Preservation Task Force Report. http://www.interpares.org/book/ interpares_book_f_part3.pdf (accessed 29/4/2015)

National competence baseline, Croatian version 3.0, Zagreb: Croatian association for project management. 2008. Page 15. http://capm.hr/preuzimanja/ (accessed 30/4/2015)

Preparations for eCTD and implementation of digital archival information system. 17/9/2014, http://www.safu.hr/en/news/preparations-for-ectd-and-implementation-of-digital-archivalinformation-system (accessed 30/4/2015)

Rajh, A. Sustavi za upravljanje digitalnom dokumentacijom - nove mogućnosti i novi izazovi za stvaratelje i arhive, Arhivski vjesnik (Bulletin d'archives) 58/2015 (Manuscript submitted for publication, forthcoming 2015)

Reference model for an open archival information system (OAIS), Recommended practice CCSDS 650.0-M-2. June 2012, http://public.ccsds.org/publications/archive/650x0m2.pdf, p. 5-3 (accessed 30/4/2015)

Shahani, C. J., Manns, B., Youket, M. Longevity of CD media: Research at the Library of Congress, Preservation of Electronic Records: New Knowledge and Decision-Making: Post Prints of a Conference, Symposium 2003, 197-206. Ottawa: Canadian Conservation Institute, 2005. http://www.loc.gov/preservation/resources/rt/studyofCDlongevity.pdf, (accessed 23.7.2015)

Slattery, O.; Lu, R.; Zheng, J.; Byers, F.; Tang, X. Stability Comparison of Recordable Optical Discs - A Study of Error Rates in Harsh Conditions, Journal of Research of the National Institute of Standards and Technology, Volume 109, Number 5, September-October 2004

Standard operative procedure AG-ARR-0005 Ingest of SIPs and migration of optical media, $1^{\text {st }}$ ed., HALMED, 2015

Standard operative procedure AG-OP-0053 Project management, $2^{\text {nd }}$ ed., HALMED, 2015

Stančić, H.; Rajh, A.; Tušek, M. Are optical disks suitable for LTP?, 10/13th International Conference Information Technology and Journalism Collaborative Media and Content Management 15-23/5/2008

Stančić, H. Theoretical model of persistent preservation of authenticity of digital information objects, PhD dissertation. Zagreb: Faculty of humanities and social sciences, 2005

Shepherd, Elizabeth i Yeo, Geoffrey, Managing records - a handbook of principles and practice. London: Facet Publishing, 2003

Turner, J.R. (edt), Gower Handbook of Project Management, Aldershot: Gower, 2007 